\title{
Behavior activities of Macrobrachium rosenbergii (De Man, 1879) in monosex and mixed populations, in the laboratory
}

\author{
Daniele Bezerra dos Santos • Lúcia Maria de Almeida • \\ Emerson Eduardo Silva de Moura • Maria de Fátima Arruda • Cibele Soares Pontes
}

DB Santos (Corresponding author) - LM Almeida

Centro Universitário Facex (UNIFACEX), Campus Capim Macio, Rua Orlando Silva, 2896, Natal, RN, Brazil.

email: danielebezerra@gmail.com

\section{EES Moura - CS Pontes}

Universidade Federal do Rio Grande do Norte (UFRN), Campus Macaíba, RN 160, Km 03, Distrito de Jundiaí, Caixa Postal 07, 59280-000, Macaíba RN Brazil.

\author{
MF Arruda \\ Universidade Federal do Rio Grande do Norte (UFRN), \\ Campus Central, Natal, RN Brazil.
}

Received: September 25, 2017 • Revised: January 12, 2018 • Accepted: January 19, 2018

\begin{abstract}
Monosex all-male populations for the commercial breeding of the freshwater prawn Macrobrachium rosenbergii have been used to lessen the specimens' aggressiveness and size heterogeneousness. The species's behavioral variation in mixed, monosex all-male and monosex all-female populations, during the 24-h light-dark period, is assessed. The focal method, with instantaneous report, was employed, featuring a 15-m window for each aquarium, distributed in 12 time shifts throughout the light-dark phase. Eight aquariums contained four prawns each (10 prawns $\left./ \mathrm{m}^{2}\right)$, totaling 96 prawns, monitored for $160 \mathrm{~h}$, during 30 days. Exploring, burrowing, covering with earth, feeding, cleaning, inactivity, crawling, swimming, change and agonistic activity were analyzed. The animals showed a high rate of autogrooming and exploitation during the light and dark phases in three culture modalities, whereas burrowing occurred more frequently during the light period. Agonism was more frequent during the dark phase in all populations, although rates of monosex all-female culture were higher during the light and dark phases when compared to mixed and monosex all-male cultures. The authors recommend shelters and substrates for protection and improvement of the animals' welfare, especially during the dark shift. Since agonism was more frequent for monosex all-female culture when compared to that in mixed or monosex all-male culture, such population composition is not recommended.
\end{abstract}

Keywords: prawn, Malaysian giant, ethology, behavior

\section{Introduction}

Prawns of the genus Macrobrachium include highly important commercial species in shrimp farming and Macrobrachium rosenbergii is economically one of the most important species of decapod crustaceans (Mitra et al 2005; New et al 2010). In fact, the species is best adapted for aquaculture business due to its high quality biological features, comprising growth, omnivorousness, high fertility and fecundity rates, resistance to disease, good market acceptance due to its delicate flesh (Gupta et al 2007).

Natural populations of $M$. rosenbergii are characterized by the development and distribution of big-size animals in a well-defined social structure and morphotype variation. Prawn size variation reflects a complex population structure composed of three major male morphotypes - small males, orange-claw males and blue-claw males, which differ in morphology, physiology and behavior, with the greatest predominance of the latter types.

One of the most important impairments for the culture development of $M$. rosenbergii is the species's size heterogeneity and morphology of males in a sexually mature population (Karplus 2005). According to Preto et al (2010), a same-sized population tends towards social unstableness, with agonism and stress among specimens. Since social interactions among juveniles and among sexually mature males affect their growth (Karplus 2005; Silva and Arruda 2014), a monosex culture has been used in some countries to reduce the issue of heterogeneous growth (Nair and Salin 2012).

Research has shown that monosex culture is a feasible method for the improvement of $M$. rosenbergii yield, with excellent growth levels, productivity, specific growth rate and greater economic viability for all-male culture. Higher survival and feed conversion rates have been also reported for all-female prawn culture (Nair et al 2006; Aflalo et al 2006; Rungsin et al 2006).

The future prospective of the commercial breeding of M. rosenbergii seems to rely on monosex population farming. 
Several studies in the field of Molecular Biology have introduced new manipulation techniques to obtain monosex populations of the species (Ventura and Sagi 2012). Consequently, another important aspect to be addressed is the influence of the population's gender composition (mixed culture, monosex all-male or all-female) on the animal's behavior and growth.

In spite of social and behavioral complexity in $M$. rosenbergii populations, studies on applied ethology are rare. They may be of great help for the development of new management practices. A behavioral study applied to commercial breeding is related to the adequateness of the environment and to animal's welfare (Huntingford et al 2012). Research in applied ethology mainly aims at understanding and enhancement of such welfare, a real concern in contemporary society, recommended by the International Society for Applied Ethology (Millman et al 2004).

Ethological studies have been applied to shrimp farming (Pontes and Arruda 2005a, 2005b; Pontes et al 2006; Lima et al 2009; Silva et al 2012; Santos et al 2013; Silva and Arruda 2014; Santos et al 2015; Santos and Pontes 2016), particularly for freshwater shrimps of the genus Macrobrachium. In fact, several research works deal with the prawn's morphology (Brody et al 1980; Cohen et al 1981; Ra'Anan and Cohen 1985; Ra'Anan and Sagi 1985; Kuris et al 1987; Ra'Anan et al 1991), agonism (Barki et al 1991; Sousa and Singer-Brugiolo 2001; Balasundaram et al 2004; Short 2004; Karplus 2005), zootechnical performance (Du and Niu 2003; Lan et al 2006) and animal performance in monosex cultures (Nair et al 2006; Santos et al 2015). Further, issues on the frequency and variation in behavioral activities for the species $M$. rosenbergii in monosex and mixed populations during the dark-light photoperiods have only been scantily analyzed. Current analysis describes variation in behavioral activities of $M$. rosenbergii in mixed and monosex populations during a 24-h period.

\section{Materials and Methods}

Adult prawns of the species $M$. rosenbergii $(27.06 \pm$ $8.41 \mathrm{~g}$ ) were harvested from fish ponds of the Aquaculture Research Station of the Agrarian Sciences Specialized Unit of the Universidade Federal do Rio Grande do Norte (UFRN), Macaíba RN Brazil. Prawns were conditioned in 80L plastic boxes and transferred to the Laboratory for Study in Prawn Behavior (LECC) of the Department of Physiology, of the Universidade Federal do Rio Grande do Norte (UFRN), Brazil. Prawns were weighed on a digital scale and marked with silicone rings on the ocular peduncle.

The animals were distributed in $250 \mathrm{~L}$ glass aquariums. Eight $250 \mathrm{~L}$ aquariums $(50 \mathrm{~cm} \times 50 \mathrm{~cm} \times 100 \mathrm{~cm})$ were employed for each treatment, within a closed system of continuous filtration and water circulation (Canister filter).
The aquariums were submitted to an artificial 12-h light/dark cycle, using a timer. In one laboratory, the light cycle was equivalent to the natural photoperiod; in another laboratory, an inverted photoperiod was employed, or rather, four experimental units in the light phase and four in the dark phase were simultaneously tracked. In the case of the inverted photoperiod, white 32-watt fluorescent lamps and red 15-watt incandescent lamps were respectively used in the light and dark phases. Two different kinds of lamps were employed due to the prawn's non-reactivity to red luminosity (Pontes and Arruda 2005).

Based on stocking density commonly used by producers for mixed populations (5 to 10 prawns. $\mathrm{m}^{-2}$ ), each aquarium received four specimens $\left(8\right.$ prawns. $\left.\mathrm{m}^{-2}\right)$. The appendage in the second pleopod pair in males was taken into account to sort the animals by gender. In studies on the variation of behavioral activities, the experimental design comprised the application of three treatments (mixed, monosex all-male and monosex all-female cultures) and four replications of each experimental condition in the light and dark phases of the photoperiod. In monosex treatments, the male appendage on the second pleopod pair was the parameter for the division of the animals by sex.

Monitoring started after a 10-day adaptation period to the aquarium's physical conditions (Pontes et al 2006) and after the establishment of the prawns' social hierarchy (Fero et al 2007). Prawns were fed from troughs (transparent acrylic trays) on $10 \%$ biomass/day, with pellet rations containing $35 \%$ crude protein (Camaronina 35 - Agribrands do Brasil Ltda.), given twice a day, at randomized periods, to avoid the interference of feed on behavioral activities.

The focal instantaneous sampling method (Martin and Bateson 2007) was employed in 15-minute windows for each aquarium, with instantaneous recording at every 60 seconds. Two observers simultaneously collected data on check sheets during light and dark phases until the 8 aquariums of each population were observed (four during the light phase and four during the dark phase), during six periods, throughout the light and dark phases, with $1 \mathrm{~h}$ report for each period. Lots were drawn at the beginning of the day to determine the aquariums that would be recorded by each observer at each observation window. Reliability tests performed by the observers produced $93 \%$ accuracy in all parameters.

Observation periods in the two phases were distributed as follows: $1^{\text {st }}$ period (immediately after change of phase $-6 \mathrm{~h}$ $7 \mathrm{~h} / 18 \mathrm{~h}-19 \mathrm{~h}) ; 2^{\text {nd }}$ period ( $2 \mathrm{~h}$ after change of phase $-8 \mathrm{~h}$ $9 \mathrm{~h} / 20 \mathrm{~h}-21 \mathrm{~h}) ; 3^{\text {rd }}$ phase (after $4 \mathrm{~h}-10 \mathrm{~h}-11 \mathrm{~h} / 22 \mathrm{~h}-23 \mathrm{~h}$ ); $4^{\text {th }}$ period (after $6 \mathrm{~h}-12 \mathrm{~h}-13 \mathrm{~h} / 0 \mathrm{~h}-01 \mathrm{~h}) ; 5^{\text {th }}$ period (after $8 \mathrm{~h}-14 \mathrm{~h}$ $15 \mathrm{~h} / 2 \mathrm{~h}-3 \mathrm{~h}) ; 6^{\text {th }}$ period (after $10 \mathrm{~h}-16 \mathrm{~h}-17 \mathrm{~h} / 4 \mathrm{~h}-5 \mathrm{~h}$ ). Behavioral categories comprised exploring substrate, digging, burrowing, feed ingestion, grooming (cleaning), inactivity, crawling, swimming, ecdysis and agonism (Santos and Pontes 2016). Ninety-six M. rosenbergii prawns were observed (32 
animals in mixed culture (males + females); 32 animals in monosex all-male culture; 32 animals in monosex all-female culture, totaling $160 \mathrm{~h}$ of observation during 30 days).

Abiotic parameters were taken daily, at 11:00. Water salinity was kept at $0 \mathrm{~g} / \mathrm{L}$ (portable refractometer); $\mathrm{pH}$ at $8.2 \pm$ 0.2 (pH-meter); temperature at $27.7^{\circ} \mathrm{C} \pm 1$ (electrode thermometer); ammonia at $0.13 \pm 0.06 \mathrm{mg} / \mathrm{L}$; dissolved oxygen over $5 \mathrm{mg} / \mathrm{L}$ (oximeter). Water quality was kept constant during the entire period, at the best level for the culture of the species (New et al 2010). Animal survival with different sizes was reported (Bautista-Teruel et al 2003).

SIGMASTAT 3.1 (2004) (Systat, Erkrath, Germany) and SIGMAPLOT 10.0 (2006) were employed for statistical analysis. Results were analyzed with data parameter (Normality - Kolmorov-Smirnov; Homoscedasticity Shapiro-Wilks test) (Zar 1999), ANOVA or Kruskal-Wallis, followed by Tukey's post-hoc test, Dunn's or StudentNewman-Keuls test, at $\mathrm{p}<0.05$. The analysis of the data was done through the Univariate Analysis of Variance test and the main effect of the behavioral variables was evaluated: mixed and monosex (all-male and all-female) culture in the light and dark phases of the 24-hour period.

\section{Results}

Mixed culture

There were significant differences between experimental activities by $M$. rosenbergii during the 24-h light period (Kruskal-Wallis, $\mathrm{H}=2172.486$; $\mathrm{gl}=9$; $\mathrm{P}=<0.001$; post-hoc Dunn's, $\mathrm{P}<0.05$ ) (Figure 1). Survival rate reached $84.38 \%$ in mixed culture (males and females). Highest occurrence rates (episodes.min ${ }^{-1}$ ) for autogrooming, mean $2.61 \pm 3.03$, were followed by burrowing, exploration, inactivity, crawling and agonism. Behavior types such as feed ingestion, swimming, digging and ecdysis were less relevant, with no statistically significant difference.

$\underline{\text { Table } 1 \text { Initial mean weight of prawns }(\mathrm{g}) \pm \text { standard deviation }}$

\begin{tabular}{lc}
\hline Treatment & Weight $(\mathrm{g})$ \\
\hline Mixed culture & $26.40 \pm 9.02$ \\
Monosex all-male culture & $26.84 \pm 9.76$ \\
Monosex all-female culture & $27.95 \pm 6.23$ \\
\hline *There was no statistical difference between treatments (ANOVA, $\mathrm{P}=0.754)$.
\end{tabular}

Differences in activities $(\mathrm{P}<0.001)$ were registered in prawns' behavior in mixed culture, during the dark phase (Figure 2). Inactivity (2.63 \pm 3.23$)$ was significantly higher than the other factors, followed by cleaning $(1.88 \pm 2.351)$,

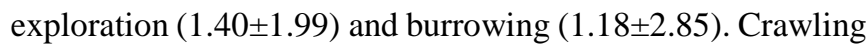
$(0.86 \pm 1.50)$, agonism $(0.61 \pm 1.09)$, swimming $(0.60 \pm 1.85)$, feed ingestion $(0.14 \pm 0.66)$ and digging $(0.01 \pm 0101)$ were less relevant during the phase $(\mathrm{H}=1933.124 ; \mathrm{gl}=9 ; \mathrm{P}=<0.001$, post-hoc Dunn's, $\mathrm{P}<0.05)$.

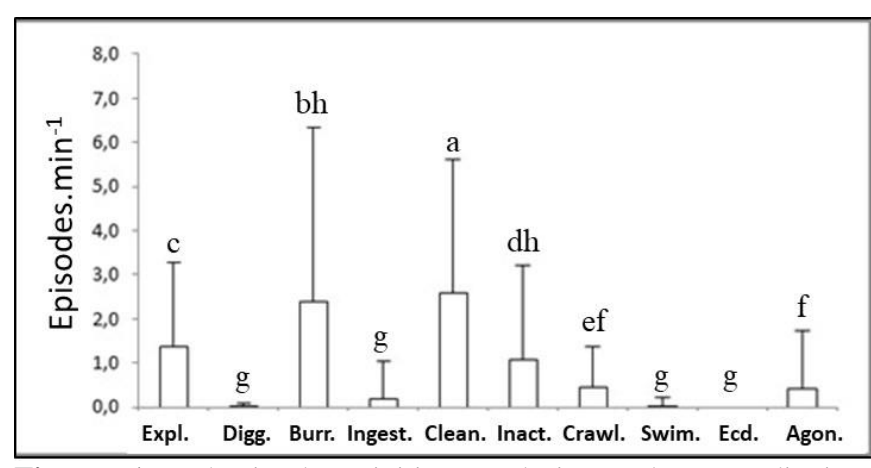

Figure 1 Behavioral activities exploring substrate, digging, burrowing, feed ingestion, autogrooming (cleaning), inactivity, crawling, swimming, ecdysis and agonism (mean \pm standard deviation) of $M$. rosenbergii in mixed culture (males and females), during the $24 \mathrm{~h}$ light period (6h-18h). Different letters denote statistical difference (Dunn's, $\mathrm{P}<0.05$ ).

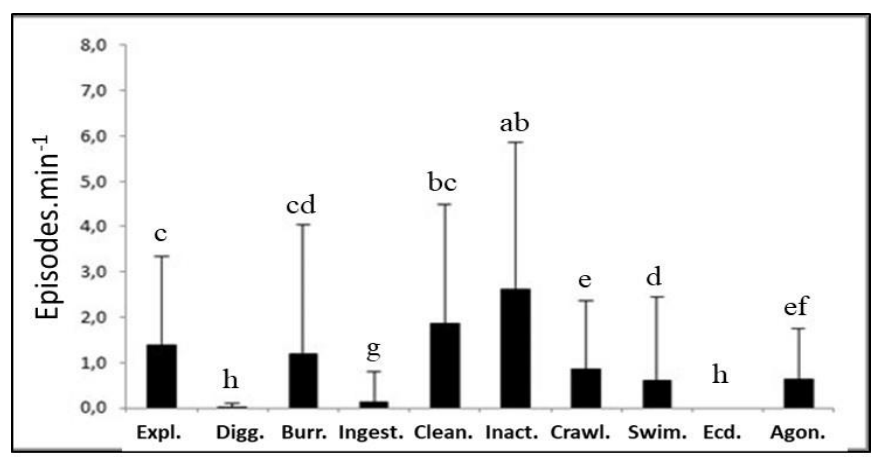

Figure 2 Behavioral activities exploring substrate, digging, burrowing, feed ingestion, autogrooming (cleaning), inactivity, crawling, swimming, ecdysis and agonism (mean \pm standard deviation) of $M$. rosenbergii in mixed culture (males and females), during the $24 \mathrm{~h}$ dark period (18h-6h). Different letters denote statistical difference (Dunn's, $\mathrm{P}<0.05$ ).

No difference existed for exploration (Kruskal-Wallis, $\mathrm{H}=5.021 ; \mathrm{gl}=11 ; \mathrm{P}=0.910$ ) and digging (Kruskal-Wallis, $\mathrm{H}=11.983 ; \mathrm{gl}=11 ; \mathrm{P}=0.364)$ during the $24 \mathrm{~h}$ period. However, behavior variations occurred in burrowing between observation periods (Kruskal-Wallis, $\mathrm{H}=45.011$; $\mathrm{gl}=11$; $\mathrm{P}=$ $<0.001$ ), with a greater burrowing trend during the light period.

Feed ingestion was similar in all observation periods (Kruskal-Wallis, $\mathrm{H}=20.788 ; \mathrm{gl}=11 ; \mathrm{P}=0.033$ ). Prawns were mostly idle during the dark phase of the day, with no difference during the periods (Kruskal-Wallis, $\mathrm{H}=132.111$; $\mathrm{gl}=11 ; \mathrm{P}=0.001$, post-hoc Student-Newman-Keuls, $\mathrm{P}<0.05$ ). Autogrooming was also reported during all periods, with highest means during the light phase, with significant differences between the periods (Kruskal-Wallis, $\mathrm{H}=50.138$; $\mathrm{gl}=11 ; \mathrm{P}=0.001$, post-hoc Student-Newman-Keuls, $\mathrm{P}<0.05)$.

Crawling occurred during all periods, but greater occurrence in the dark phase (Kruskal-Wallis, $\mathrm{H}=72.132$; $\mathrm{gl}=11 ; \mathrm{P}=<0.001$, post-hoc de Dunn's, $\mathrm{P}<0.05$ ), but with statistical differences between the periods (Kruskal-Wallis, $\mathrm{H}$ $=141.355 ; \mathrm{gl}=11 ; \mathrm{P}=0,001$, post-hoc Student-Newman- 
Keuls, $\mathrm{P}<0.05)$. Crawling was more frequent during the dark phase of the day, with highest occurrence at $18 \mathrm{~h}$. There was no difference between periods 20:00, 22:00, 00:00, 02:00 and 04:00 h.

Prawns were agonistic at all periods, with greatest occurrence during the dark phase and highest levels at 18:00 h (Kruskal-Wallis, $\mathrm{H}=224.101 ; \mathrm{gl}=11 ; \mathrm{P}=0.001$, post -hoc Student-Newman-Keuls, $\mathrm{P}<0.05)$.

Monosex all-male culture

M. rosenbergii's behavior activities in monosex allmale culture feature different means throughout the light phase (Kruskal-Wallis, $\mathrm{H}=2297.077 ; \mathrm{gl}=9 ; \mathrm{P}=<0.001$, post hoc Dunn's, $\mathrm{P}<0.05)$. Grooming episodes occurred more frequently (2.61 \pm 3.01$)$, followed by burrowing, exploration, inactivity, crawling and agonism (Figure 3). Feed ingestion, swimming, digging and ecdysis were less frequent, without any difference. Survival reached $81.25 \%$ at this stage.

Differences between types of behavior occurred in the dark phase $(\mathrm{H}=1779.221 ; \mathrm{gl}=9 ; \mathrm{P}=<0.001$, post-hoc Dunn's).

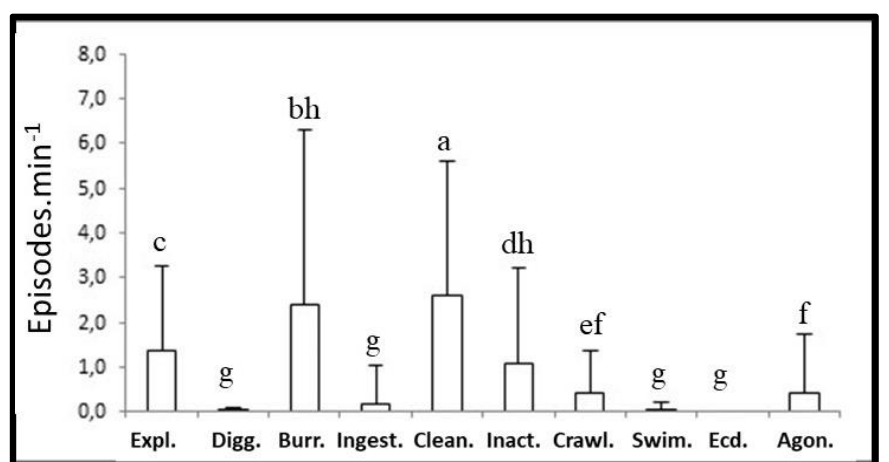

Figure 3 Behavioral activities: exploring substrate, digging, burrowing, feed ingestion, autogrooming (cleaning), inactivity, crawling, swimming, ecdysis and agonism (mean \pm standard deviation) of $M$. rosenbergii in monosex all-male culture, during the 24h light (6h-18h). Different letters denote statistical difference (Dunn's, $\mathrm{P}<0.05$ ).

Behavior types were analyzed according to observation periods. There was no difference in exploration (KruskalWallis, $\mathrm{H}=4.899$; $\mathrm{gl}=11 ; \mathrm{P}=0.929$ ) and digging (KruskalWallis, $\mathrm{H}=10.897 ; \mathrm{gl}=11 ; \mathrm{P}=0.455)$ during the $24 \mathrm{~h}$ photoperiod. Differences for burrowing occurred in periods between the light and dark period (Kruskal-Wallis, $\mathrm{H}=$ 44.099; $\mathrm{gl}=11 ; \mathrm{P}=<0.001$, Tukey's post-hoc test, $\mathrm{P}<0.05$ ), with greatest frequency during the light period.

Feed ingestions differed during the observation period (Kruskal-Wallis, $\mathrm{H}=19.895 ; \mathrm{gl}=11 ; \mathrm{P}=<0.045$ ) at all periods, with highest frequency at 08:00 h, 12:00 h, 22:00 h and 04:00 h (Student Newman-Keuls, $\mathrm{P}<0.05$ ).

Autogrooming was reported at all periods, with highest frequency rates during the light phase (Kruskal-Wallis, $\mathrm{H}=$
55.093; gl=11; $\mathrm{P}=0.001$, post-hoc Student-Newman-Keuls, $\mathrm{P}<0.05)$. Prawns tended to be less active during the dark phase (Kruskal-Wallis, $\mathrm{H}=122.734 ; \mathrm{gl}=11 ; \mathrm{P}=0.001$, post-hoc Student-Newman-Keuls, $\mathrm{P}<0.05$ ), with highest decreasing rates for 02:00 h, 00:00 h, 4:00 h, 22:00 h and 20:00 h.

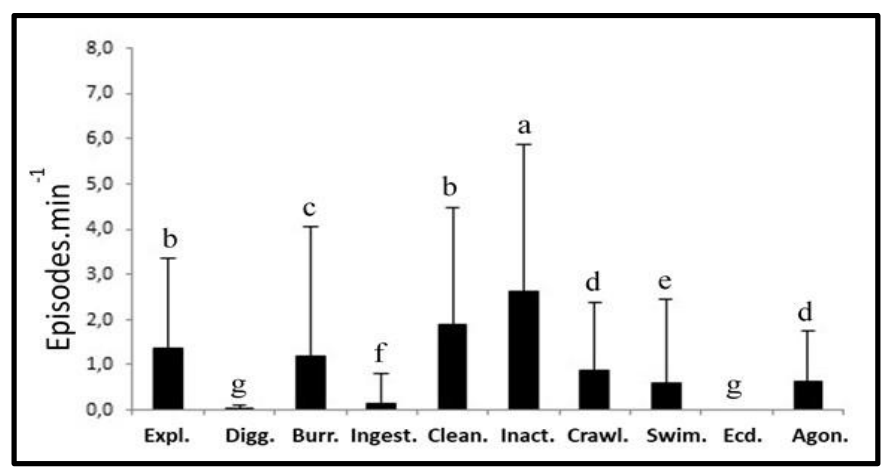

Figure 4 Behavioral activities exploring substrate, digging, burrowing, feed ingestion, autogrooming (cleaning), inactivity, crawling, swimming, ecdysis and agonism (mean \pm standard deviation) of $M$. rosenbergii in mixed culture (males and females), during the $24 \mathrm{~h}$ dark period (18h-6h). Different letters denote statistical difference (Dunn's, $\mathrm{P}<0.05$ ).

There were differences in animal displacement behavior (crawling and swimming). Crawling occurred at all periods, with highest frequency during the dark phase (Kruskal-Wallis, $\mathrm{H}=73.032 ; \mathrm{gl}=11 ; \mathrm{P}=<0.001$, post-hoc Student-Newman-Keuls, $\mathrm{P}<0.05)$. Swimming was more frequent during the dark phase, with highest occurrence at 18 h (Kruskal-Wallis, $\mathrm{H}=133.666 ; \mathrm{gl}=11 ; \mathrm{P}=0.001$, post-hoc Student-Newman-Keuls, $\mathrm{P}<0.05)$.

Although prawns exhibited agonism at all periods, its greatest occurrence occurred during the dark phase, with highest peak at 18:00 h (Kruskal-Wallis, $\mathrm{H}=177.889$; $\mathrm{gl}=11$; $\mathrm{P}=0.001$, post-hoc Student-Newman-Keuls, $\mathrm{P}<0.05)$.

Monosex all-female culture

There were significant differences with regard to types of behavior during the light (Kruskal-Wallis, $\mathrm{H}=2799.555$; $\mathrm{gl}=9 ; \mathrm{P}=<0.001$, post hoc Tukey, $\mathrm{P}<0.05)$ and dark phases ( $\mathrm{H}=2999.668 ; \mathrm{gl}=9 ; \mathrm{P}=<0.001$, post-hoc Dunn's) (Figure 7 and 8). Higher grooming occurrences (episodes. min $^{-1}$ ) occurred (3.60 \pm 3.17 ), followed by burrowing, inactivity, exploration, agonism and crawling. Behavior types, such as feed ingestion, swimming, digging and ecdysis, were less salient, with no differences between them. Survival reached $100 \%$ in monosex all-female culture.

\section{Discussion}

The prawns explored the environment homogeneously at all periods and in all three culture systems (mixed, monosex all male and monosex all-female). Similar behavior has been 
registered by Pontes et al (2006) and Santos et al (2013) with regards to $L$. vannamei. Reports on inactivity are more frequent during the dark phase, with the exception of the monosex all-female population. Digging was detected in the three culture systems, during the two phases, and always close to shelters. According to Dall et al (1990), digging is a flight and protection strategy. Substrate type is very important and favors such behavior.

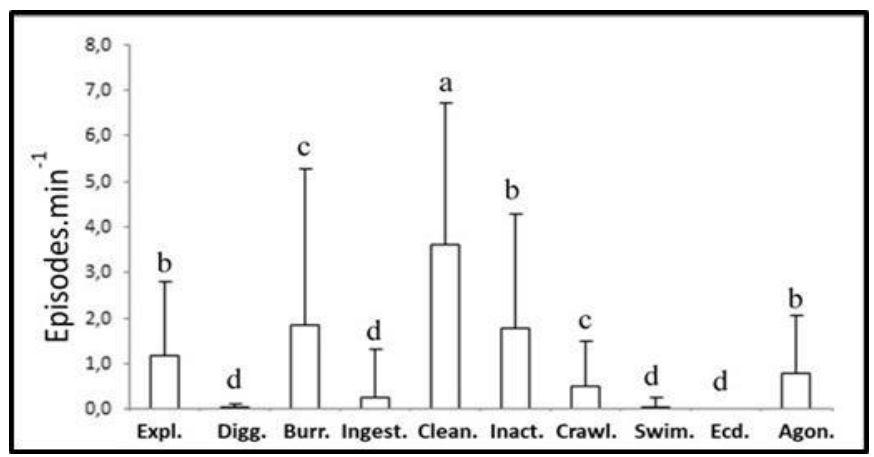

Figure 5 Behavioral activities exploring substrate, digging, burrowing, feed ingestion, autogrooming (cleaning), inactivity, crawling, swimming, ecdysis and agonism (mean \pm standard deviation) of $M$. rosenbergii in monosex all-male culture, during the $24 \mathrm{~h}$ light period $(6 \mathrm{~h}-18 \mathrm{~h})$. Different letters denote statistical difference (Dunn's, $\mathrm{P}<0.05$ ).

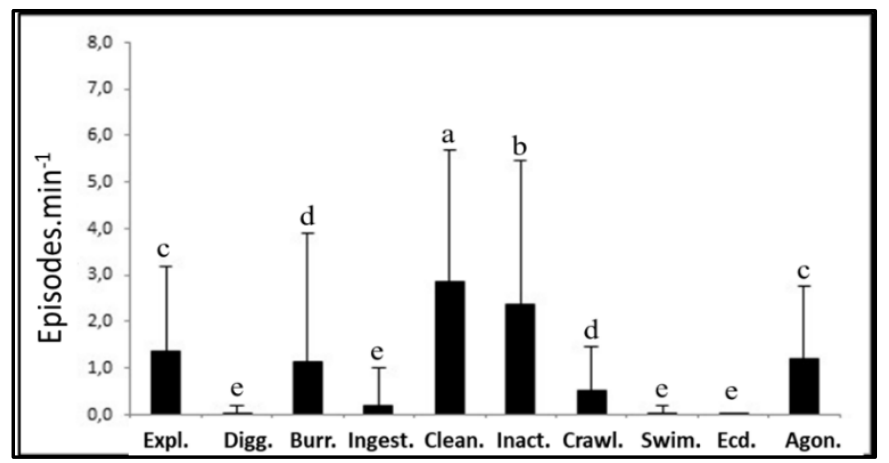

Figure 6 Behavioral activities exploring substrate, digging, burrowing, feed ingestion, autogrooming (cleaning), inactivity, crawling, swimming, ecdysis and agonism (mean \pm standard deviation) of $M$. rosenbergii in monosex all-female culture, during the $24 \mathrm{~h}$ dark period (18h-6h). Different letters denote statistical difference (Dunn's, $\mathrm{P}<0.05$ ).

Burrowing in shelters tended to be more frequent during the light phase, with highest rates for mixed and monosex all-male cultures. Crustacean normally live in cracks and holes, under stones or in empty gastropod shells (Stein 1977) since they protect specimens in agonistic encounters within intra- and inter-species interactions (Soderback 1994). Shelters are relevant resources to decrease agonistic encounters and predation since they provide protection for weak specimens in the presence of dominant males (Englund and Krupa 2000). Balasundaram et al (2004) have shown that prawns of the genus Macrobrachium (Macrobrachium nobilli and Macrobrachium malcolmsonii) also have a burrowing behavior and remain for a longer period during the light phase.
Santos et al (2015) analyzed the behavior scale of $M$. rosenbergii in mixed cultures with colored shelters and reported that multi-colored shelters for $M$. rosenbergii - black for males and orange or red for females - are recommended for the breeding of the species. Agonistic encounters decrease during the light phase of the day. According to Alcock (2010), taking possession of and defending a shelter are important factors to avoid predation. Access to food and mating is made easier. According to Balasundaram et al (2004), the burrowing behavior of animals with a high degree of cannibalism and aggressiveness should be understood to discover dominance pattern in the acquisition and defense of the shelter.

Autogrooming scored highest in the three types of culture (mixed, monosex all-male and monosex all-female) during light and dark phases of the $24 \mathrm{~h}$ period. According to Bauer (1989), several decapod crustacean species spent much time and energy in cleaning. Karplus et al (1992) analyzed social interaction of $M$. rosenbergii males and demonstrated that high autogrooming rates are due to the confinement of the animals in the aquarium's small space required for the assay. Further, the closeness of a dominant prawn may affect such behavior.

According to Dantzer and Mittleman (1993), autogrooming is a displaced behavior, undertaken out of context and compulsively for stress relief. Current analysis shows that the high occurrence of stress-caused autogrooming may be related to aquarium size (small space), closeness of another specimen of the same species, presence of microorganisms in the exoskeleton, communication mechanisms. Below agonism, grooming featured the most frequent activity by prawns. Long-term studies should be undertaken to understand such behavior for survival or reproduction.

In their research on the behavior of $M$. rosenbergii, Van Maurik and Wortham (2014) argue that foraging, fighting a predator or a co-specific specimen, and mating, are normally deemed primary behavior types and are usually considered high in behavioral hierarchy as they are evolutionarily relevant for reproductive fitness and survival conditions. Secondary behavior types occur when primary behavior ones are not crucial, such as body grooming, which is a behavioral adaptation to fouling pressures. In fact, secondary behaviors may be inhibited when more vital types of behavior are crucial for survival. Furthermore, organisms in resource-limiting environments or social situations (i.e. competition, mating, agonistic interactions) give priority to behaviors with the greatest resource profitability. Therefore, yields depend on the size of the hierarchical groups in the grow-out tanks or ponds. Research, therefore, demonstrated that prawns' autogrooming is a secondary behavior. It is an antifouling adaptation, particularly in high-density populations, such as aquaculture settings. 
Current analysis revealed that feeding did not affect other behavior activities since ration was administered at random periods. Feeding behavior was reported during all periods, with no statistical difference during the 24-h period. Nunes et al (1996) and Pontes and Arruda (2005) corroborated the above results on feed ingestion and reported that the shrimps Farfantepenaeus subtilis and L. vannamei ingested feed during the day and night periods.

Displacement rates by crawling (substrate) and swimming (water column) were higher during the dark period. Prawns avoid displacement during the light period to avoid predators. Since prawns have different habitats throughout their life cycle and, consequently, migrate between several habitats, displacement is one of the basic parameters that affect their survival. This is true for migratory species, particularly performance, swimming speed and climate conditions which determine migration limits and the time required for such movements (Dall et al 1990; Pontes et al 2006; Freire et al 2011; Santos et al 2013).

Swimming is the main characteristic for the survival of water organisms in an aquatic environment. Zhang et al (2007) reported the same behavior pattern shown by Litopenaeus vannamei (juveniles; male and female adults), with greater swimming frequency during the dark phase. Pontes et al (2006) and Freire (2011) reported the same displacement and swimming patterns, respectively, for $L$. vannamei and Xiphopenaeus kroyeri.

Prawns migrate and swim through several environments during their life cycle (Vinatea-Arana 2004). The prawns' activity is also determined by the light/dark cycle (24 h). Field research has shown that prawns dig and burrow during the light phase, confirmed in the laboratory for the species X. kroyeri (Freire et al 2011) and L. vannamei (Pontes et al 2005; Pontes 2006; Lima et al 2009; and Santos et al 2013). The literature does not report any research on the behavior of swimming or crawling for freshwater prawns. Current analysis shows that crawling and swimming during the dark phase may be related to their search for resources, such as feed or mates, and prey avoidance. Further research is needed to investigate the exploratory activities of prawns with regard to the presence or absence of limited resources.

Current analysis revealed that prawns are highly aggressive during the dark phase according to greater levels of agonistic exhibitions by specimens in mixed, monosex allmale and monosex all-female populations. Further, the monosex all-female culture showed the highest agonistic rates during the light and dark phases when compared to those for mixed and monosex all-male cultures. Current results contrast those by Karplus et al (1992), Short (2004) and Karplus (2005) who attribute the males of the species with the highest aggression levels.

Researchers in animal behavior underscore that aggression is part and parcel of social interaction called agonistic behavior, characterized by threats to specimens of the same or different species by an individual or a group of individuals (Deag 1981). Aggressiveness in dominating specimens affects the behavior of other specimens of the same population. So that fatal encounters with subordinate specimens could be avoided, some animals keep to shelters (Englund and Krupa 2000).

Barki et al (1991) observed 5,551 agonistic acts between $M$. rosenbergii prawns in a $40-\mathrm{h}$ recording and established dominance and subordination behavior types by cluster analysis. According to these authors, the three main components of agonistic acts in $M$. rosenbergii comprise claws positioning and movement, body raising and direction towards the other specimen. In several crustacean species, the second pereiopod pair (chelae) was the main component of several agonistic displays (Dingle 1983). Experimental analyses (Hazlett 1979; Dunhan 1981) have demonstrated the value of the communication position of the chelae and coloration.

According to Bergman and Moore (2005), chemical and visual signs are employed to communicate the social status and, consequently, alter the aggressive behavior of potential enemies to avoid aggressive interactions, forecasting the result of the interactions. The smallest incidence of agonism for monosex all-male and mixed culture in current research is related to the establishment of clear visual morphological clues of dominance among males, avoiding detrimental and unnecessary behaviors. The crustacean specimen which starts an attack is considered more aggressive. However, the specimen must be victorious in the struggle to be considered a dominant specimen within the population (Bergman et al 2003).

Since current analysis revealed a survival rate above $80 \%$ in all treatments, it revealed that, in spite of agonistic interactions, a reasonable survival rate in all treatments is directly linked to good water quality, food quality and quantity, and the prawns' capacity of acquiring feed (Armstrong et al 1972). In fact, M. rosenbergii prawns were exposed to a daily light-dark cycle and kept under constant experimental conditions in relation to physical-chemical water parameters, such as water current, barometric pressure and others, presumably cyclical components of the natural environment. The cyclicality of behavior types is certainly a prime factor for the interaction of animals undergoing changes in the environment they inhabit. Results showed that the species's adult prawn developed activities during the light and dark phases, even though activity is differentiated by specific types of behavior. Since agonistic behavior was more frequent during the dark phase in all populations, the authors recommend shelters and substrates for the protection and welfare of the animals, especially during the dark phase. Further, since agonistic behavior was more frequent during the dark phase for monosex all-female culture system when 
compared to monosex all-male and mixed cultures, such population composition should be shunned.

\section{Acknowledgements}

The authors would like to thank the Conselho Nacional de Desenvolvimento Científico e Tecnológico (CNPq). Thanks are also due to the Post-Graduate Program in Psychobiology (Animal Behavior) (UFRN).

\section{References}

Aflalo ED, Hoang TTT, Nguyen VH, Lam Q, Nguyen DM, Trinh Q, Raviv S, Sagi A (2006) A novel two-step procedure for mass production of all-male populations of the giant freshwater prawn Macrobrachium rosenbergii. Aquaculture 256:468-478.

Alcock J (2010) Comportamento animal: uma abordagem evolutiva. Artmed, Porto Alegre.

Armstrong DA, Stephenson MJ, Knight AW (1972) Acute toxicity of nitrite to larvae of giant Malaysian prawn Macrobrachium rosenbergii. Aquaculture 9:39-46.

Balasundaram C, Jeyachitra P, Balamurugan P (2004) Shelter preference in Macrobrachium spp. with reference to aquaculture. Acta Ethologica 7:95-101.

Barki A, Karplus I, Goren M (1991) The Agonistic Behaviour of the Three Male Morphotypes of The Freshwater Prawn Macrobrachium rosenbergii (Crustacea, Palaemonidae). Behaviour 116:3-4.

Bauer RT (1989) Decapod crustacean grooming: functional morphology, adaptive value, and phylogenetic significance. In: Felgenhauer B, Watling L, Thistle R (eds) Functional morphology of feeding and grooming in Crustacea. 6rd edn. Balkema AA, Rotterdam, pp 49-73.

Bautista-Teruel MN, Eusebio PS, Welsh TP (2003) Utilization of feed pea, Pisum sativum, meal as a protein source in practical diets for juvenile tiger shrimp, Penaeus monodon. Aquaculture 225:121131.

Bergman DA, Kozlowski CP, Mcintyre JC, Huber R, Daws AG, Moore PA (2003) Temporal dynamics and communication of winner-effects in the crayfish, Orconectes rusticus. Behaviour 140:805-825.

Bergman, DA, Moore PA (2005) The role of Chemical Signals in the social behavior of crayfish. Chemical senses 30:305-306.

Brody T, Cohen D, Barnes A, Spector A (1980) Yield characters of Macrobrachium rosenbergii monoculture. Aquaculture 21:375-385.

Cohen D, Ra'Anan Z, Brody T (1981) Population perfil development and morfhotypic differentiation in the giant freshwater prawn Macrobrachium rosenbergii (de Man). Journal of the World Mariculture Society 12:231-243.

Dall W, Hill BJ, Rothlisberg PC, Staples DJ (1990) The biology of the Penaeidae. In: Blaxster JHS \& Southard AJ (eds). Advances in Marine Biology. Academic press, San Diego.

Dantzer R, Mittleman G (1993) Functional consequences of behavioural strategy. In: Lawrence $\mathrm{AB} \&$ Rushden J (eds). Stereotypic animal behaviour: fundamentals \& applications. $\mathrm{CAB}$ International, Oxford, pp 147-172.

Deag JM (1981) Comportamento social dos animais. Pedagógica e Universitária, São Paulo.
Dingle H (1983) Strategies of agonistic behaviour in crustacean. In: Studies of adaptation: The behavior of hihger crustacean. Wiley, New York, pp 85-111.

Du L, Niu CJ (2003) Effects of dietary substitution of soya bean meal for fish meal on consumption, growth, and metabolism of juvenile giant freshwater prawn, Macrobrachium rosenbergii. Aquaculture Nutrition 9:139-143.

Dunhan DW (1981) Chela efficiency in display and feeding by hermit crabs (Decapoda, Paguridae). Crutaceana 41:40-45.

Englund G, Krupa JJ (2000) Habitat use by crayfish in stream pools: influence of predators, depth and body size. Freshwater Biology 43:75-83.

Fero K, Simon JL, Jourdie V, Moore PA (2007) Consequences of social dominance on crayfish resource use. Behaviour 144:61-82.

Freire FAM, Luchiari AC, Fransozo V (2011) Environmental substrate selection and daily habitual activity in Xiphopenaeus kroyeri shrimp (Heller, 1862) (Crustacea: Penaeioidea). Indian Journal of GeoMarine Sciences 40:325-33.

Gupta A, Singh HS, Kaur GS (2007) Growth and carcass composition of giant freshwater prawn, Macrobrachium rosenbergii (De Man), fed different isonitrogenous and isocaloric diets. Aquaculture Research 38:1355-1363.

Hazlett BA (1979) The meral spot of Gonodactylus oerstedii as a visual stimulus. Crustaceana 36:196-198.

Huntingford F, Jobling M, Kadri S (2012) Aquaculture and behavior. Blackwell Publishing, Oxford.

Karplus I (2005) Social control of growth in Macrobrachium rosenbergii (De Man): a review and prospects for future research. Aquaculture Research 36:238-254.

Karplus I, Hulata G, Ovadia D, Jaffe R (1992) Social control of growth in Macrobrachium rosenbergii. III. The role of claws in bullrunt interactions. Aquaculture 105:281-296.

Kuris AM, Ra'Anan Z, Sagi A, Cohen D (1987) Morfhotypic differentiation of male malasyan giant prawns Macrobrachium rosenbergii. Journal of Crustacean Biology 7:219-237.

Lan LM, Long DN, Micha J (2006) The effects of densities and feed types on the production of Macrobrachium rosenbergii (de Man) in the rotational rice-prawn system. Aquaculture Research 37:12971304.

Lima PP, Pontes CS, Arruda MF (2009) Activity pattern of the marine shrimp Litopenaeus vannamei (Boone 1931) in laboratory as a function of different feeding frequencies. Aquaculture Research 41:53-60.

Martin P, Bateson P (2007) Measuring behaviour: an introductory guide. 3rd ed. Cambridge University, Cambridge.

Millman ST, Duncan IJH, Stauffacher M, Stookey JM (2004) The impact of applied ethologists and the International Society for Applied Ethology in improving animal welfare. Applied Animal Behaviour Science 86:299-311.

Mitra G, Chattopadhyay DN, Mukhopadhyay PK (2005) Nutrition and feeding in freshwater prawn (Macrobrachium rosenbergii) farming. Aqua Feeds: Formulation and Beyond 2:17-19.

Nair CM, Salin (2012) Current status and prospects of farming the giant river prawn Macrobrachium rosenbergii (De Man) and the monsoon river prawn Macrobrachium malcolmsonii in India. Aquaculture Research 43:999-1014. 
Nair CM, Salin KR, Raju MS, Sebastian M (2006) Economic analysis of monosex culture of giant freshwater prawn (Macrobrachium rosenbergii De Man): a case study. Aquaculture Research 37:949-954.

New MB, Valenti WC, Tidwell JH, D’Abramo LR, Kutty MB (2010) Freshwater prawns: biology and farming. Wiley-Blackwell, Oxford.

Nunes AJP, Goddard S, Gesteira TCV (1996) Feeding activity patterns of the Southern brown shrimp Penaeus subtilis under semiintensive culture in NE Brazil. Aquaculture 44:371-386.

Pontes CS, Arruda MF (2005a) Comportamento de Litopenaeus vannamei (Boone) (Crustacea, Decapoda, Penaeidae) em função da oferta do alimento artificial nas fases claras e escuras do período de 24 horas. Revista Brasileira de Zoologia 22:648-652.

Pontes CS, Arruda MF (2005b) Acesso ao alimento artificial e enchimento do trato digestivo do camarão marinho Litopenaeus vannamei (Boone) (Crustacea, Decapoda, Penaeidae) durante as fases clara e escura do período de 24 horas. Revista Brasileira de Zoologia 22:1039-1043.

Pontes CS, Arruda MF, Menezes AAL, Lima PP (2006) Daily activity pattern of the marine shrimp Litopenaeus vannamei (Boone 1931) juveniles under laboratory conditions. Aquaculture Research 37:1001-1006.

Preto BL, Kimpara JM, Valenti P, Valento WC (2010) Population structure of pond-raised Macrobrachium amazonicum with different stocking and harvesting strategies. Aquaculture 307:206-211.

Ra'Anan Z, Cohen D (1985) Ontogeny of social structure and population dynamics in the giant freshwater prawn, Macrobrachium rosenbergii (De Man). In: Wenner AM (ed.) Factors in adult growth. A. A. Balkema, Boston, pp 277-31.

Ra'Anan Z, Sagi A (1985) Alternative mating strategies in males of the freshwater prawn Macrobrachium rosenbergii (De Man). Biological Bulletin 69:592-601.

Ra'Anan Z, Sagi A, Wax Y, Karplus G, Hulata GT, Kuria A (1991) Growth, size rank, and maturation of the freshwater prawn, Macrobrachium rosenbergii: analysis of marked prawns in an experimental population. Biological Bulletin 181:379-386.

Rungsin W, Paankhao N, Natthapong NA, Nakorn U (2006) Production of all-male stock by neofemale technology of the Thai strain of freshwater prawn, Macrobrachium rosenbergii. Aquaculture 259:88-94.

Santos DB, Freire FAM, Pontes CS (2013) Comportamento do camarão em diferentes substratos nas fases clara e escura do dia. Revista de Pesquisa Agropecuária Brasileira 48:841-848.

Santos DB, Pontes CS (2016) Behavioral repertoire of the giant freshwater prawn Macrobrachium rosenbergii (De Man, 1879) in laboratory. Journal of Animal Behaviour and Biometeorology 4:109115 .

Santos DB, Pontes CS, Campos PMO, Arruda MF (2015) Behavioral profile of Macrobrachium rosenbergii in mixed and monosex culture submitted to shelters of different colors. Acta Scientiarium, Biological Sciences 37:273-279.

Silva PF, Arruda MF (2014) Social status and individual behavioral differences in juvenile Macrobrachium rosenbergii. Marine and Freshwater Behaviour and Physiology 8: 1-11.

Silva PF, Medeiros MF, Silva HPA, Arruda MF (2012) A study of feeding in the shrimp Farfantepenaeus subtilis indicates the value of species level behavioral data for optimizing culture management. Marine and Freshwater Behaviour and Physiology 45:121-134.
Soderback B (1994) Interaction among juveniles of two freshwater crayfish species and a predatory fish. Oceologia 100:229-235.

Sousa MC, Singer-Brugiolo SS (2001) Efeito da amputação das quelas sobre o comportamento canibalístico de Macrobrachium rosenbergii (De Man, 1879) (Crustacea, Palaemonidae) em condições de laboratório. Revista Brasileira de Zoociências 3:7-19.

Stein RA (1977) Selective predation, optimal foraging and the predator prey interaction between fish and crayfish. Ecology 58:1237-1253.

Van Maurik LN, Wortham JL (2014) Grooming as a secondary behavior in the shrimp Macrobrachium rosenbergii (Crustacea, Decapoda, Caridea). ZooKeys 457:55-77.

Ventura T, Sagi A (2012) The insulin-like androgenic gland hormone in crustaceans: From a single gene silencing to a wide array of sexual manipulation-based biotechnologies. Biotechnology Advances 30:1543-1550.

Vinatea-Arana LA (2004) Fundamentos de Aquicultura. EDUFSC, Florianópolis.

Zar JH (1999) Bioestatistical analysis. Prentice-hall, New Jersey.

Zhang P, Hang P, Zhang X, Li J, Huang G (2007) The effects of temperature and salinity on the swimming ability of white leg shrimp, Litopenaeus vannamei. Comparative Biochemistry and Physiology 147:64-69, 2007. 